\title{
Four-point bending cycling as alternative for Thermal cycling solder fatigue testing
}

\author{
Bart Vandevelde $^{\mathrm{a}}$, Filip Vanhee ${ }^{\mathrm{b}}$, Davy Pissoort ${ }^{\mathrm{b}}$, Lieven Degrendele ${ }^{\mathrm{c}}$, Johan De Baets ${ }^{\mathrm{c}}$, Bart Allaert ${ }^{\mathrm{d}}$, Ralph \\ Lauwaert $^{\mathrm{e}}$, Riet Labie ${ }^{\mathrm{a}}$, Geert Willems ${ }^{\mathrm{a}}$

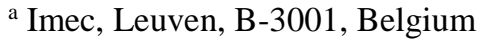 \\ ${ }^{\mathrm{b}}$ KULeuven-KHBO, Oostende, Belgium \\ ${ }^{\mathrm{c}}$ Imec, Ghent, Belgium \\ ${ }^{\mathrm{d}}$ Connect Group, Ieper, Belgium \\ ${ }^{\mathrm{e}}$ Interflux Electronics, Ghent, Belgium
}

bart.vandevelde@imec.be, tel. +32 16281513

\begin{abstract}
This paper deals with an alternative testing approach for quantifying the life time of board level solder joint reliability of components. This approach consists of applying a relative shear displacement between component and Printed Circuit Board (PCB) through cyclic board bending. During the cycling, the temperature is kept constant, preferably at elevated temperature in order to fasten the creep deformation of the solder joint. This is done in a four-point bending setup which allows to apply an equal loading on all components lying between the inner bars. The scope of the paper is, firstly, to evaluate if the four point bending testing generates the same fatigue fracture as in thermal cycling; secondly, that the measured life times can be also predicted through finite element simulations; and thirdly if the technique can finally fasten the cycling frequency to gain testing time.
\end{abstract}

\section{Introduction to alternative testing for thermal cycling}

Thermal cycling testing is a widely spread method for analyzing the board level thermal cycling performance of printed board assemblies. Thermal cycling testing is part of basically all qualification standards.

However, thermal cycling testing for analysing the second level solder joint reliability is a time consuming experiment. Acceleration of the test in order to fasten the failures is only possible through increasing temperature swing. This is done either through increasing the maximum temperature closer to the melt, or decreasing the minimum temperature making the solder more brittle. Both too high or too low temperature can lead to new failure modes which may not be relevant for the operational conditions the system has to work.

In order to cope with these limitations, an alternative testing approach has been developed and evaluated in this work. The method is based on applying four-point bending applied to the Printed Circuit Board (PCB). The bending causes an absolute displacement at the top/bottom fibre of the PCB and as such applies a displacement mismatch with the component which is similar to what is seen during temperature cycling. The bending system is installed in a thermal chamber which allows to combine bending and thermal cycling. In first instance, we kept the temperature constant during the cycling.

Jedec provides a standard for Board Level Cyclic Bend Test Method for Interconnect Reliability Characterization of Components for Handheld Electronic Products [1]. They mention that the test procedure is presently more appropriate for relative component performance than for use as a pass/fail criterion. It is also not meant for life time estimations nor for assembly qualifications.

\section{Analytical equations relating the applied bending parameters to the local strain on the solder joints}

In a thermal cycling experiment with a temperature swing of $\Delta \mathrm{T}$, the displacement mismatch between the PCB and component at each joint locations is calculated as follows

$$
\Delta l_{P C B-\operatorname{Comp}}=D N P *\left(C T E_{P C B}-C T E_{C o m p}\right) * \Delta T
$$

with DNP is the distance to neutral point, typically the center of the component. The CTE of the PCB is a weighted average for the FR4 and the copper layers, the CTE of the component is also a weighted average, however more difficult to calculate due to the asymmetry of the package build-up. The joints seeing the highest DNP are typically the corner joints.

The objective with the 4-point bending cycling methodology is to apply in the four point bending experiment the same relative displacement between the PCB and the component.

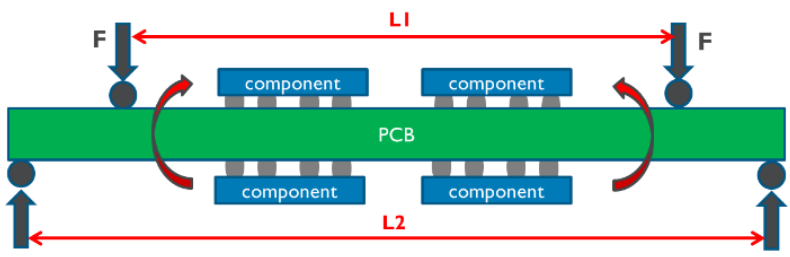

This is achieved by the PCB bending strain $\varepsilon_{\mathrm{PCB}}$ in the top/bottom layer and is equal to

$$
\epsilon_{P C B}=\frac{1}{\rho} \frac{h_{P C B}}{2}
$$


with $1 / \rho$ is the curvature ( $\rho$ is the radius of curvature) and $h_{\mathrm{PCB}}$ is the PCB thickness. Similar to equation (1), the strain can be translated into a relative displacement per cycle between component and PCB:

$$
\Delta l_{P C B-C o m p}=D N P * 2 * \frac{1}{\rho} \frac{h_{P C B}}{2}
$$

The factor 2 is added as in one cycle, the board is bent from $-1 / \rho$ to $+1 / \rho$ curvature which doubles the relative displacement.

In order to achieve the same load in the four point bending as for the thermal cycling, the applied curvature should be

$$
\frac{1}{\rho}=\frac{\left(C T E_{P C B}-C T E_{C o m p}\right) * \Delta T}{h_{P C B}}
$$

The parameter which is applied in the four point bending experiment is the displacement $\delta$ of the moving inner bars relative to the static outer bars.

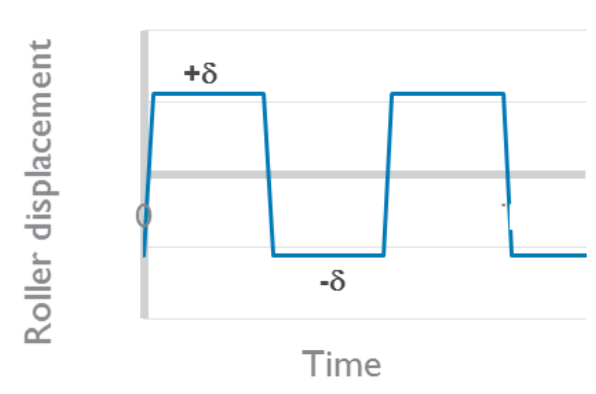

This deflection is calculated as follows:

$$
\delta=\frac{F *\left(\frac{L_{2}-L_{1}}{2}\right) *\left(3 * L_{2}{ }^{2}-4 *\left(\frac{L_{2}-L_{1}}{2}\right)^{2}\right)}{24 * E_{P C B} I_{P C B}}
$$

with $\mathrm{F}$ is force applied on one bar (so total force applied by the motor is $2 \mathrm{~F}$ ), $\mathrm{E}_{\mathrm{PCB}}$ is the elastic modulus of the $\mathrm{PCB}$ and $\mathrm{I}_{\mathrm{PCB}}$ is the moment of inertia of the PCB.

The bending moment applied to the PCB in the area between the two inner bars is constant and equal to:

$$
M=F \frac{L_{2}-L_{1}}{2}
$$

This bending moment results in a curvature (in the inner area) equal to

$$
\frac{1}{\rho}=\frac{M}{E_{P C B^{* I}} I_{P C B}}
$$

Combining equations 5, 6 and 7, the curvature can written as function of the applied bar displacement $\delta$ as follows

$$
\frac{1}{\rho}=\frac{24}{\left(3 * L_{2}^{2}-4 *\left(\frac{L_{2}-L_{1}}{2}\right)^{2}\right)} \delta
$$

which translates into a strain on the top fiber using equation 2:

$$
\epsilon_{P C B}=\frac{12 * h_{P C B}}{\left(3 * L_{2}{ }^{2}-4 *\left(\frac{L_{2}-L_{1}}{2}\right)^{2}\right)} \delta
$$

In order to apply the same strain hysteresis per cycle as for the temperature cycle, the bar displacement $\delta$ can be defined as function of the $\Delta \mathrm{T}$ through

$$
\delta=\left[\frac{\left(C T E_{P C B}-C T E_{C o m p}\right)\left(3 * L_{2}{ }^{2}-4 *\left(\frac{L_{2}-L_{1}}{2}\right)^{2}\right)}{24 * h_{P C B}}\right] * \Delta T
$$

\section{Description of the four point bending testing setup and test vehicle}

The four-point bending system consists of four pairs of rollers as shown schematically in. The board under test is clamped between each pair of rollers which are in turn tightened together as shown in. An aluminum plate makes the connection of the inner rollers to the linear actuator. The outer rollers are fastened to a thick aluminum plate which is clamped inside the climate chamber. By moving the actuator either up or down, the board is bended in the likewise direction.

The displacement of the board is measured on the inner rollers which are attached to the actuator by an aluminum plate.

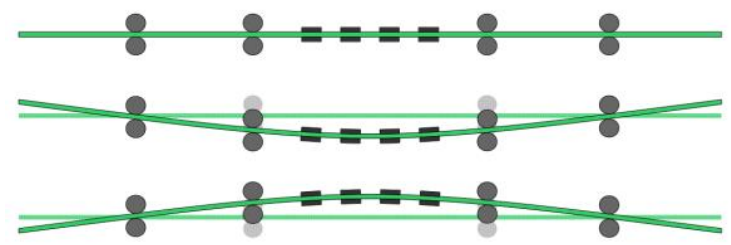

Figure 1: Schematic drawing visualizing the concept of the four point bending cycling

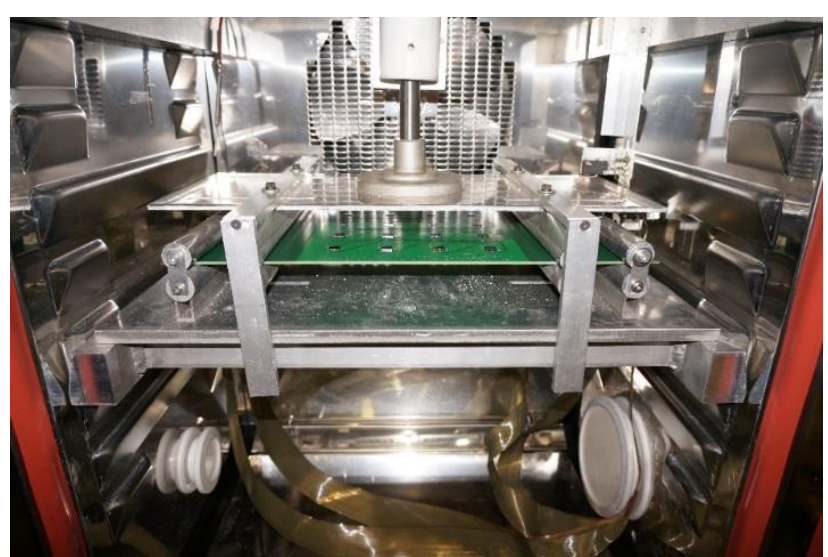

Figure 2: Realization of the four point bending setup in the thermal chamber 
The bending test board measures $450 \mathrm{~mm}$ by $280 \mathrm{~mm}$ and is $2.5 \mathrm{~mm}$ thick. The daisy chain components are located in the spacing between the load anvils, which is about $210 \mathrm{~mm}$ wide. On each side of the board, 20 daisy chain components have been placed in an array of 4 columns and 5 rows. This number is limited by the number of channels of the measurement equipment, not by the space. It was chosen to have the same component soldered at both sides in order to have a symmetric build-up. This is important for the bending experiment in order to guarantee that the neutral fiber remains in the middle of the PCB.

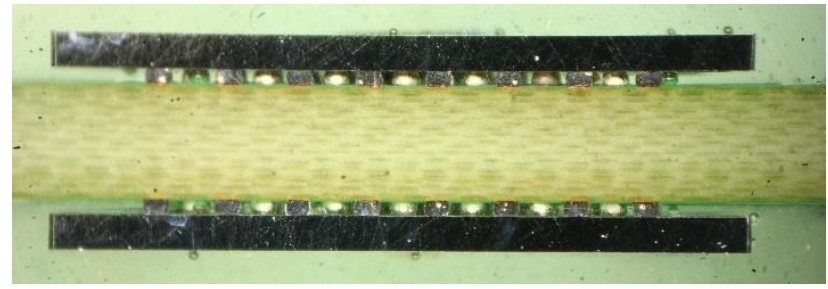

Figure 3: Cross-section (over the diagonal) of the CSP's soldered at both sides of the PCB.

\section{One-to-one comparison: $4 p t$ bending versus thermal cycling}

The same component assembly has been tested under isothermal temperature cycling and 4-point bending cycling. The details of the test conditions are summarized in Table 1. It was decided to apply only half of the strain in the four point bending as for the thermal cycling. This means that in this 4 point bending test, a strain is applied equal which loads the solder joint with the same shear displacement as in a thermal cycling with a $\Delta \mathrm{T}$ of $50^{\circ} \mathrm{C}$.

\section{Table 1: Conditions for thermal and bending cycling}

\begin{tabular}{|c|c|c|}
\hline \multicolumn{1}{|c|}{ Test } & Conditions & $\begin{array}{c}\text { Applied strain } \\
\text { (AlPCB-Comp/DNP) }\end{array}$ \\
\hline $\begin{array}{c}\text { Thermal } \\
\text { cycling }\end{array}$ & $\begin{array}{c}0 \text { to } 100^{\circ} \mathrm{C} \text { cycling } \\
20 \text { min dwell time }\end{array}$ & $0.14 \%$ \\
\hline $\begin{array}{c}\text { Bending } \\
\text { cycling }\end{array}$ & $\begin{array}{c}\mathrm{T}=100^{\circ} \mathrm{C}\left(\mathrm{C}^{\mathrm{te}}\right) \\
\delta=5.6 \mathrm{~mm}(\mathrm{roller} \\
\text { displacement } \\
20 \text { min dwell time }\end{array}$ & $0.07 \%$ \\
\hline
\end{tabular}

The results of the tests are shown in the Weibull distribution in Figure 4. The samples in the 4pt bending test are failing much earlier than the thermal cycling, although the applied shear load on the joint is only half. This is explained by the fact that the bending test is performed at a constant temperature of $100^{\circ} \mathrm{C}$, allowing the material to have much more creep.

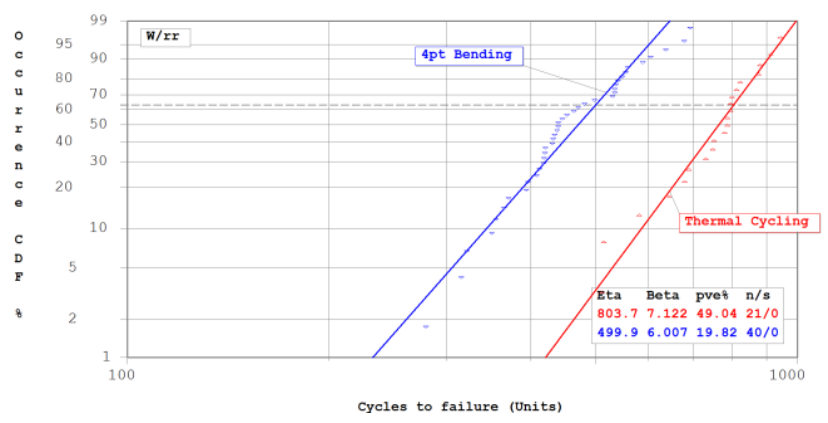

Figure 4: Weibull distribution for the two cycling techniques

Cross-sections of failed samples for the two testing methods show a similar fatigue fracture, located close to the CSP (see Figure 5 and Figure 6).

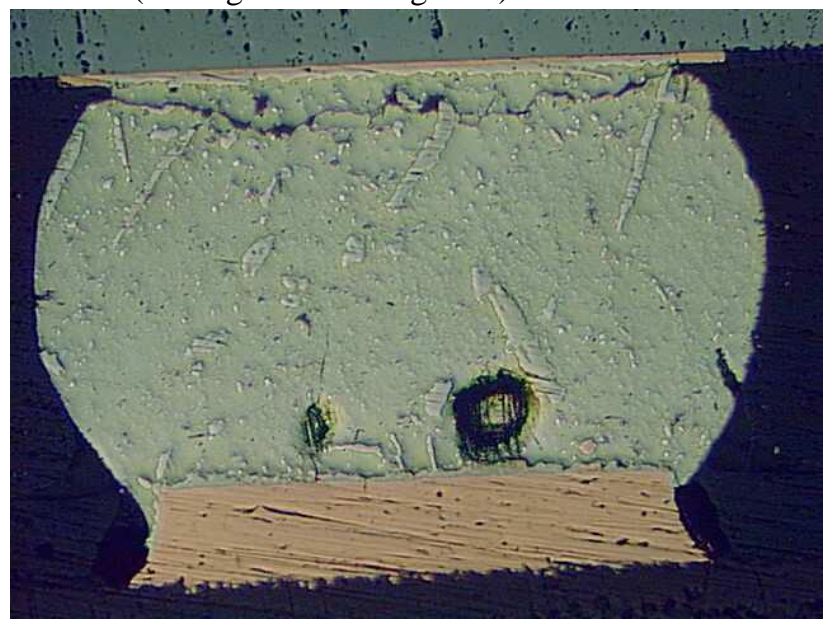

Figure 5: Cross-section of failed solder joint after thermal cycling testing

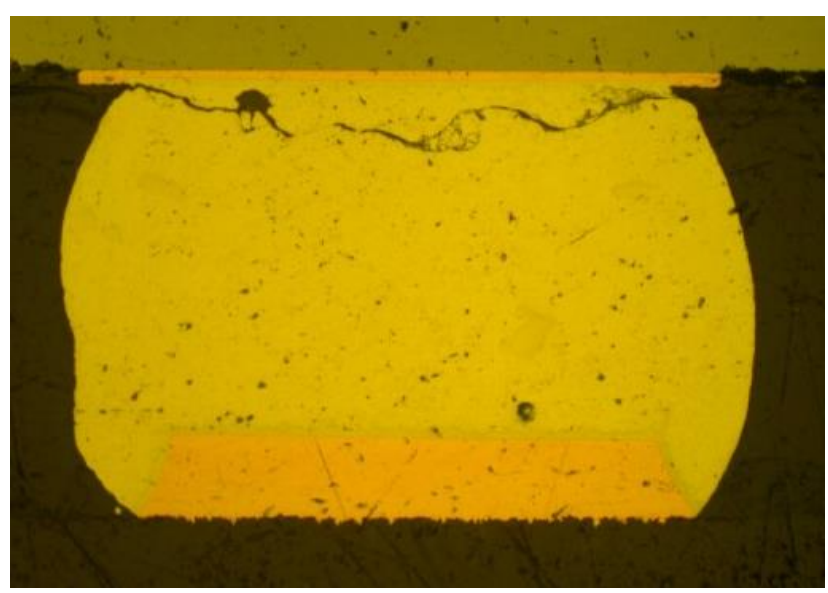

Figure 6: Cross-section of failed solder joint after 4pt bending cycling testing.

In order to understand why 4-pt bending leads to much faster failures than thermal cycling, a thermo-mechanical simulation was performed with the same testing conditions. The simulation model for $4 \mathrm{pt}$ bending test is shown in Figure 7. The SAC305 solder material is modelled using the ANAND based equations defining the 
viscoplastic behaviour as function of temperature and stress [2]. Viscoplasticity is defined as unifying plasticity and creep via a set of flow and evolutionary equations where a constraint equation is used to reserve volume in the plastic region.

$$
f_{\text {secs }}^{\text {cous }}
$$

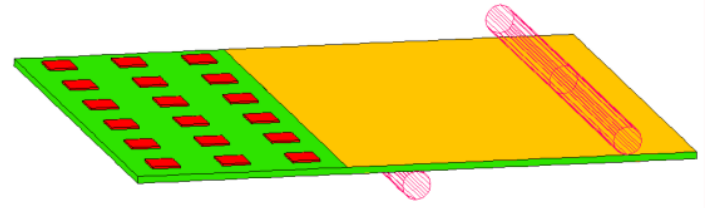

Figure 7: Finite Element Model simulating the 4-point bending test

The output of interest from this simulation is the creep strain distribution induced in one thermal (Figure 8) or one bending (Figure 9) cycle.

In the thermal cycle, the corner joints see the highest creep strains. This is in agreement with the experiments showing the first failures in one of the four corners.

In the bending cycle, the two outer rows are equally stressed. Comparing the creep strains to the thermal cycling case, the strains are about $10 \%$ more stressed in the 4 pt bending case. This already confirms the trend seen in the experiments. However the little difference in creep strain per cycle cannot explain the factor in the life time. The latter one is explained when we take the statistics into account. In the thermal cycling, the four corner joints are equally stressed. In the four point bending cycling, in total 16 joints are seeing the highest stress. As the daisy chain fails when one joint is fractured, it is expected to have faster failures in a larger population. Taking this into account can explain the factor 2 seen in experiments.

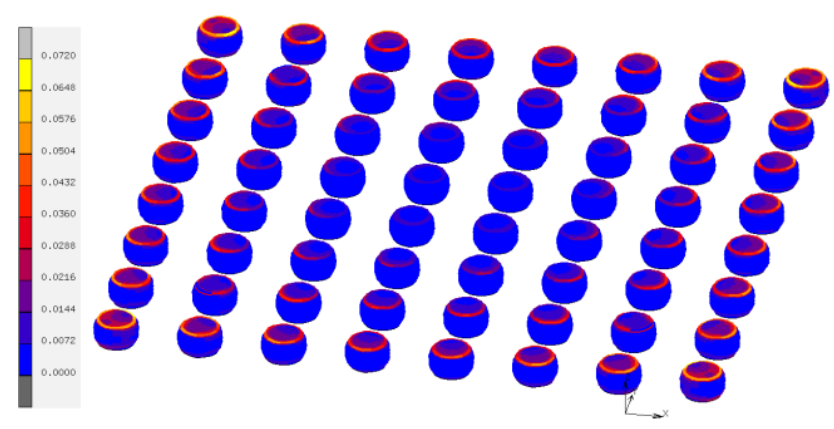

Figure 8: Creep strain in the solder joints induced over one thermal cycle $\left(0\right.$ to $\left.100^{\circ} \mathrm{C}\right)$.

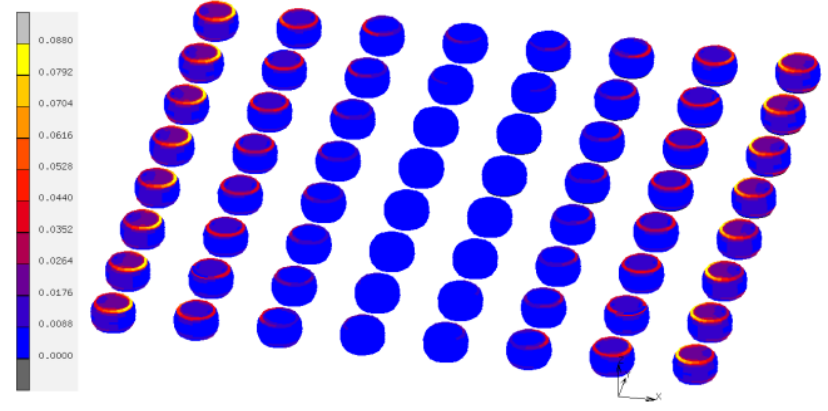

Figure 9: Creep strain in the solder joints induced over one bending cycle (see table 1 for exact conditions).

\section{4pt bending tests with varying dwell time}

The major advantage of the 4-pt bending test would be that cycling could be done at higher frequency reducing the testing time. Increasing this frequency can be achieved through reducing the dwell time. In order to quantify this impact, bending fatigue tests have been performed on the same component assemblies with dwell times varying from $30 \mathrm{sec}$ to 20 minutes. The results are summarised into a Weibull plot (Figure 10). There is no difference seen between 20 and 10 minutes dwell time. With fast cycling (30 sec and 30 minutes), the life time increase by about a factor 2 . In this case, we could say that 10 minutes dwell is more than sufficient. This is of course temperature dependent as at other temperature, creep of the solder is different and therefore could need more or less time to have full relaxation of the solder joint.

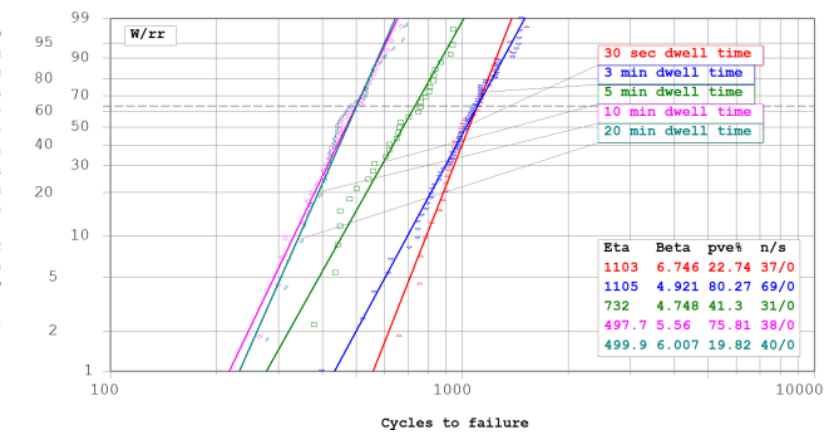

Figure 10: Weibull plot for 4 point bending cycling tests with different dwell times

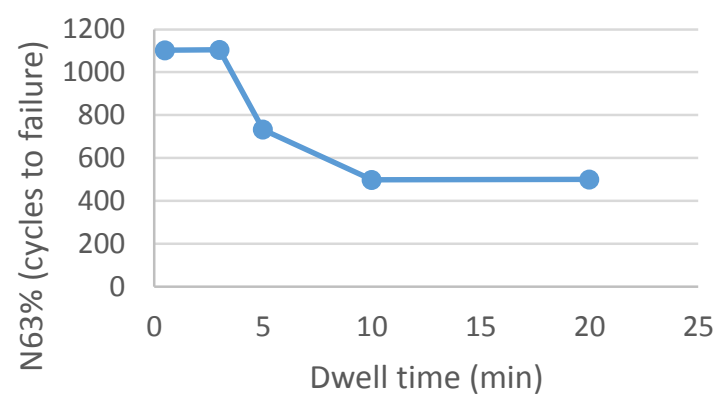

Figure 11: Relation between characteristic life and dwell time during the 4pt bending test 


\section{Conclusions}

$4 \mathrm{pt}$ bending experiments have been performed on test boards with 24 soldered daisy chain WL-CSP's. Solder joint fractures are seen after a number of bending cycles and are similar to fractures induced due to temperature cycling. The time to failure of the PCB could be related to the applied bending strain. As it is also the objective to reduce the testing time, the effect of the dwell time is measured, showing an increase in number of cycles for a dwell time below 10 minutes.

With 4-pt bending cycling, the test time could be reduced by a factor of three. The technique even allows to further accelerate without the danger to initiate new failure modes. It is therefore a suitable technique to derive acceleration models.

\section{Acknowledgments}

This work has been supported by the Vlaio (Flemish government) through the REV-UP project. The authors would like to thanks Raf Verberne for his support on the cross-sectional analysis of the failed samples.

\section{References}

1. "Board Level Cyclic Bend Test Method for Interconnect Reliability Characterization of Components for Handheld Electronic Products", JESD22B113 JEDEC standard.

2. K. Mysore, G. Subbarayan, V. Gupta, R. Zhang, "Constitutive and Aging behaviour of $\mathrm{Sn} 3.0 \mathrm{Ag} 0.5 \mathrm{Cu}$ Solder Alloy,", in IEEE TransationsTrans. on Electronic Packaging Manufacturing, Vol.v 32, No. n4, Oct 2009, pp 221-232. 